\title{
Individual Differences in Cue-Induced Motivation and Striatal Systems in Rats Susceptible to Diet-Induced Obesity
}

\author{
Mike JF Robinson 1,2 , Paul R Burghardt ${ }^{3,4}$, Christa M Patterson ${ }^{5}$, Cameron W Nobile $^{6}$, Huda Akil ${ }^{3}$, \\ Stanley J Watson ${ }^{3}$, Kent C Berridge' and Carrie R Ferrario*,6 \\ 'Department of Psychology, University of Michigan, Ann Arbor, MI, USA; ${ }^{2}$ Department of Psychology, Wesleyan University, Middletown, CT, USA; \\ ${ }^{3}$ Molecular and Behavioral Neuroscience Institute, The University of Michigan School of Medicine, Ann Arbor, MI, USA; ${ }^{4}$ Department of Psychiatry, \\ University of Michigan School of Medicine, Ann Arbor, MI, USA; ${ }^{5}$ Division of Metabolism, Endocrinology, and Diabetes, Department of Internal \\ Medicine, University of Michigan, Ann Arbor, MI, USA; ${ }^{\circ}$ Department of Pharmacology, University of Michigan School of Medicine, Ann Arbor, MI, USA
}

\begin{abstract}
Pavlovian cues associated with junk-foods (caloric, highly sweet, and/or fatty foods), like the smell of brownies, can elicit craving to eat and increase the amount of food consumed. People who are more susceptible to these motivational effects of food cues may have a higher risk for becoming obese. Further, overconsumption of junk-foods leading to the development of obesity may itself heighten attraction to food cues. Here, we used a model of individual susceptibility to junk-foods diet-induced obesity to determine whether there are pre-existing and/ or diet-induced increases in attraction to and motivation for sucrose-paired cues (ie, incentive salience or 'wanting'). We also assessed dietvs obesity-associated alterations in mesolimbic function and receptor expression. We found that rats susceptible to diet-induced obesity displayed heightened conditioned approach prior to the development of obesity. In addition, after junk-food diet exposure, those rats that developed obesity also showed increased willingness to gain access to a sucrose cue. Heightened 'wanting' was not due to individual differences in the hedonic impact ('liking') of sucrose. Neurobiologically, Mu opioid receptor mRNA expression was lower in striatal 'hotspots' that generate eating or hedonic impact only in those rats that became obese. In contrast, prolonged exposure to junk-food resulted in cross-sensitization to amphetamine-induced locomotion and downregulation of striatal D2R mRNA regardless of the development of obesity. Together these data shed light on individual differences in behavioral and neurobiological consequences of exposure to junk-food diets and the potential contribution of incentive sensitization in susceptible individuals to greater food cue-triggered motivation.
\end{abstract}

Neuropsychopharmacology (2015) 40, 2 II3-2 I23; doi:I0.1038/npp.2015.7I; published online I5 April 2015

\section{INTRODUCTION}

Pavlovian cues associated with palatable foods (food cues), like the smell of fresh-baked brownies, carry incentive salience that makes the cues attractive, reinforcing, and able to trigger urges to eat. For example, in humans, food cues can increase ratings of desire to eat and the amount of food consumed (Fedoroff et al, 1997; Soussignan et al, 2012). Similarly, in rodents, food cues can elicit approach, reinforce operant responding (eg, conditioned reinforcement), and increase food consumption (Holland and Petrovich, 2005). However, no studies have examined cue-induced motivation in preclinical models of obesity. The recent global rise in obesity heightens the need to understand the neurobiological mechanisms governing these processes, particularly in susceptible individuals.

Clinical data suggest that some people may attribute more incentive salience (ie, motivational value) to food cues than

*Correspondence: Dr CR Ferrario, Department of Pharmacology, University of Michigan, I I 50 W. Medical Center Drive, MSRB I|| I30 I, Ann Arbor, MI 48I09, USA, Tel: +1 734945 9887, Fax: +847578 8515, E-mail: ferrario@umich.edu

Received 23 November 2014; revised 29 January 2015; accepted 23 February 2015; accepted article preview online 12 March 2015 others, and consequently be more likely to overeat and become obese (see Dagher, 2009 for review). For example, food cues more robustly enhance the desire to eat (Fedoroff et al, 1997; Tetley et al, 2009) and more strongly activate the nucleus accumbens $(\mathrm{NAc})$ and caudate putamen $(\mathrm{CPu})$ in obese people (Rothemund et al, 2007; Stoeckel et al, 2008), even prior to the development of obesity (Stice et al, 2010; Demos et al, 2012). In rodents, Pavlovian autoshaping reveals individual differences in motivated attraction to food cues (see Robinson and Flagel, 2009 for review). In autoshaping procedures, some rats (sign-trackers) are highly attracted to approach a discrete cue that predicts sugar reward, whereas other rats are instead attracted to the place (goal) where sugar is delivered (goal-trackers). To date, no studies have examined individual differences in attraction (approach) or motivation (conditioned reinforcement) for food cues in models of obesity, or determined the effect of diet-induced obesity on motivational properties of food cues, despite evidence that obese people are hyperresponsive to food cues (Rothemund et al, 2007; Stoeckel et al, 2008; Stice et al, 2010; Demos et al, 2012). Therefore here, we used a moderately fatty 'junk-food' diet that produces obesity only in a subset of susceptible rats (Levin et al, 1997) to examine both pre-existing and diet-induced alterations in approach 
and conditioned reinforcement behavior to a sucrosepaired cue.

Neurobiologically, evidence implicates dopamine and opioid systems in the NAc and CPu in obesity (Shin et al, 2011; Volkow et al, 2013b). However, it is unclear to what extent these neurochemical systems are influenced by the consumption of palatable foods $v s$ by the development of obesity. Therefore, we also examined striatal dopamine and $\mathrm{mu}$ opioid receptor mRNA and cross-sensitization to amphetamine in rats susceptible vs resistant to 'junk-food' diet-induced obesity. Importantly, our approach allows us to distinguish differences due to junk-food diet exposure alone, $v s$ those associated with obesity. Finally, we measured the hedonic response to oral sucrose to determine whether individual differences in incentive salience ('wanting') for Pavlovian cues were driven by differences in the hedonic impact ('liking') of sucrose.

\section{MATERIALS AND METHODS}

\section{Subjects}

Adult male Sprague-Dawley rats (70-75-days old) were purchased from Harlan (Exp. 1) or bred in house (Exp. 2, 3). Procedures were approved by The University of Michigan Committee on the Use and Care of Animals. Rats had free access to food and water unless explicitly noted. Body weight was measured twice per week.

\section{Experiment 1: Are there Pre-Existing Differences in Conditioned Approach Behavior in Rats Susceptible to Obesity Under Ad Lib Conditions?}

Autoshaping. Detailed procedures have been reported (Anselme et al, 2013). During training (8 sessions), the presentation of a retractable, illuminated lever accompanied by an auditory tone (CS+; $80 \mathrm{~dB} ; 8 \mathrm{~s}$ ) was followed by delivery of a sucrose pellet (25 CS+/UCS pairings, VI: $30-$ $90 \mathrm{~s})$. A second, non-illuminated control lever (CS -) remained present throughout the entire session. No behavioral responses were required to receive a sucrose pellet. This established the CS+ as a predictive cue for sucrose delivery ('sucrose cue'; $N=30$ rats). After initial approach training, all rats were transferred to the 'junk-food' diet in order to determine individual susceptibility to obesity.

Junk-food diet. The 'junk-food' diet was a mash composed of: Ruffles original potato chips ( $40 \mathrm{~g}$ ), Chips Ahoy original chocolate chip cookies (130 g), Jiff smooth peanut butter (130 g), Nesquik powdered chocolate flavoring (130 g), powdered Lab Diet 5001 (200 g; 19.6\% fat, 14\% protein, $58 \%$ carbohydrates; $4.5 \mathrm{kcal} / \mathrm{g})$, and water $(180 \mathrm{ml})$. Ingredients were combined in a food processor. These foods contain a rich mix of sugars, salt, and fats, and were chosen as palatable representatives of what are commonly called 'junk-foods' implicated in human obesity. Diet composition was closely matched to kcal/g of standard lab chow (Lab Diet 5001: $4.5 \%$ fat, $23 \%$ protein, $48.7 \%$ carbohydrates; $4 \mathrm{kcal} / \mathrm{g}$ ), and based on previous studies establishing individual differences in susceptibility to weight gain and subsequent metabolic syndrome (Levin et al, 1997). K-means clustering based on weight gain after 1 month of free access to the junk- food diet was used to identify individuals susceptible (JF-Gainer) vs resistant to diet-induced obesity (JF-Non-Gainer).

Experiment 2A: Does Food Restriction During Training Amplify Motivation for a Sucrose Cue in Susceptible Rats?

Autoshaping. Rats were food restricted throughout the initial autoshaping training $(90 \% \pm 0.5 \%$ free-feeding body weight; $N=23$ ). After initial training, rats were returned to ad lib standard chow for 1 week prior to giving some rats access to the junk-food diet. Chow $(N=10)$ and junk-food $(N=13)$ groups were counter balanced such that initial weight and age did not differ.

Post junk-food testing. Testing began after 3 months on the junk-food diet. Extinction testing was identical to autoshaping training except that no sucrose was given (25 CS+ presentations). Four additional retraining sessions followed (25 CS +/sucrose presentations) after which conditioned reinforcement for the sucrose cue was assessed in a single session (30 min; FR1). Responses in one port (active) presented the sucrose cue $(3 \mathrm{~s})$, but no sucrose pellets were delivered. Nosepokes in another port (inactive) produced no outcome. The difference in magnitude of responding between ports indicates magnitude of conditioned reinforcement.

Leptin and insulin. Fasted blood samples were collected into tubes containing EDTA $(1.6 \mathrm{mg} / \mathrm{ml}$, Sarstedt) after 15 weeks on the diets and centrifuged $\left(1000 g ; 10 \mathrm{~min}, 4^{\circ} \mathrm{C}\right)$ to isolate plasma. Samples were analyzed using a Multiplex magnetic bead panel with Luminex detection (EMD Millipore) for insulin and leptin levels.

\section{Experiment 2B: Does Prolonged Access to the Junk-Food Diet Produce Cross-Sensitization to Amphetamine?}

Locomotor activity. Amphetamine-induced locomotor activity was evaluated in a single session after 155 days on the diets (saline: $1 \mathrm{ml} / \mathrm{kg}$; d-amphetamine: $0.32,1.0,3.2$, and $5.6 \mathrm{mg} / \mathrm{kg} / \mathrm{ml}$, i.p.) in standard testing chambers equipped with an array of photocell beams.

\section{Experiment 2C: Does Junk-Food Diet Alter Dopamine and Opioid Systems in Rats Susceptible to Obesity?}

In situ hybridization. Three weeks after amphetamine exposure, brains were collected (Chow $N=10$, JF-Gainer $N=5$, JF-Non-Gainer $N=7$ ) for in situ hybridization of dopamine receptors (D1; M35077, D2; M36831), tyrosine hydroxylase (TH; M10244), the dopamine transporter (DAT; M80233), and the Mu opioid receptor (L22455; (Mansour et al, 1990; Thompson et al, 1993)). Sections beginning $+5.20 \mathrm{~mm}$ and ending $-9.30 \mathrm{~mm}$ from bregma (Paxinos and Watson, 2007) were collected and thaw-mounted onto polyL-lysine-coated slides. In situ hybridization was performed as previously described (Kabbaj et al, 2000). Autoradiographic images were digitized (Microtek Scan Maker 1000XL; Fontana, CA) and optical density was determined (Image J; $\mathrm{NIH}$; Bethesda, MD). Templates were used for each region of interest. Adjacent sections probed for TH mRNA were used to identify the VTA. 
Experiment 3: Are there Pre-Existing and/or DietInduced Differences in Hedonic Responses to Sucrose in Rats Susceptible to Obesity?

Taste reactivity. Hedonic responses to sucrose were measured using taste reactivity procedures (Ho and Berridge, 2013) in separate rats $(N=12)$. Briefly, rats were anesthetized (100 mg/kg ketamine HCL, $7 \mathrm{mg} / \mathrm{kg}$ xylazine, and $0.04 \mathrm{mg} / \mathrm{kg}$ atropine sulfate, IP) and intra-oral guide cannulae were implanted bilaterally (Ho and Berridge, 2013). Rats were postoperatively treated with chloramphenicol $(60 \mathrm{mg} / \mathrm{kg}, \mathrm{SC})$ and carprofen $(5 \mathrm{mg} / \mathrm{kg}$, SC). After recovery from surgery (7 days), rats were handled and habituated to the taste reactivity procedure ( 3 days) and then orofacial reactions to sucrose oral infusions $(1,3$ and $9 \% \mathrm{w} / \mathrm{vol})$ were evaluated. Rats were tested both prior to and after 1 month of free access to the junk-food diet, and after acute food deprivation $(10 \mathrm{~h})$. Positive, aversive, and neutral patterns of orofacial reactions to sucrose were scored using frame-by-frame digital analysis (Berridge, 2000; Ho and Berridge, 2013) conducted by a scorer blind to experimental conditions (Observer software, Noldus, Netherlands; see (Ho and Berridge, 2013) for additional details).

Statistics. For comparison of three or more groups repeated measures ANOVAs were used followed by post- tests (Prizm6; GraphPad, San Diego, CA). When JF-Gainer and JF-Non-Gainer groups did not differ, they were collapsed and compared with Chow-Fed controls. For comparisons between two groups, two-tailed paired and un-paired $t$-tests were used.

\section{RESULTS}

\section{Experiment 1}

Individual susceptibility to junk-food diet-induced weight gain. JF-Gainer $(N=7)$ and JF-Non-Gainers $(N=23)$ showed similar weight gain when given ad lib access to standard lab chow (Figure 1a, weeks 1-3) but individual differences in susceptibility to weight gain were revealed when rats were given free access to the junk-food diet (Figure 1a, weeks 4-7). This was due in part to increased junk-food intake in JF-Gainers $v s$ JF-Non-Gainers ( 10-15\% higher in JF-Gainers than JF-Non-Gainers; data not shown). Initial weight did not predict subsequent weight gain (average weight JF-Gainer $=322 \mathrm{~g} \pm 4 \mathrm{~g}$; JF-Non-Gainer $=$ $325 \mathrm{~g} \pm 2 \mathrm{~g}$; data not shown).

Rats susceptible to obesity show enhanced conditioned approach prior to junk-food diet. During Pavlovian

Gainers show enhanced conditioned approach prior to junk-food diet

a

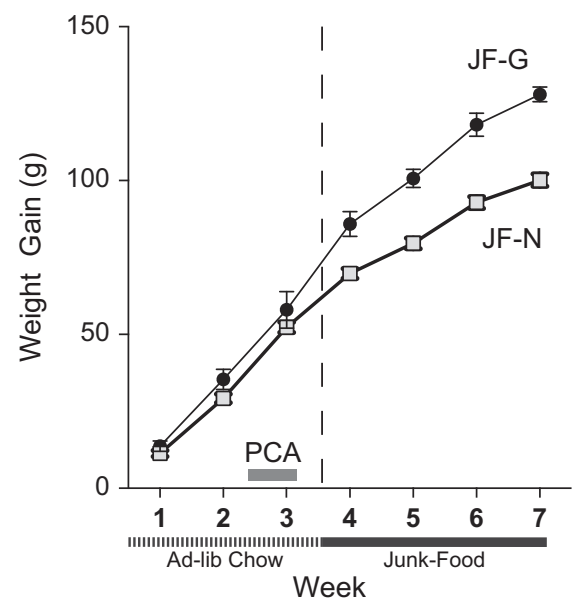

b Enhanced Conditioned Approach

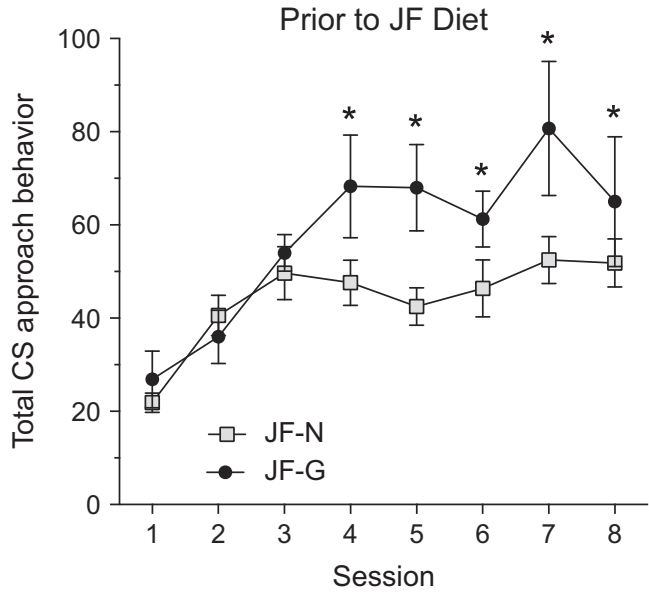

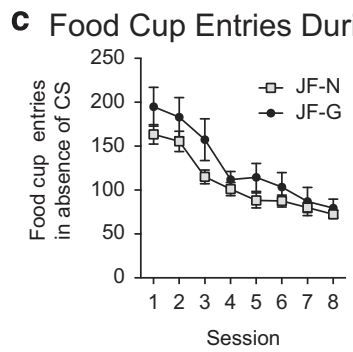
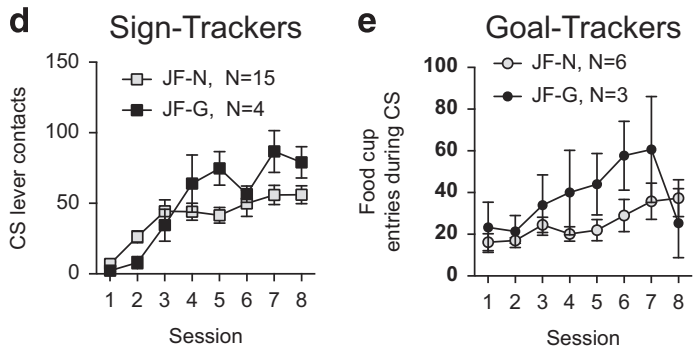

Figure I Junk-Food Gainers show enhanced conditioned approach prior to junk-food diet exposure. (a) Average ( \pm SEM) weekly weight gain prior to (week I-3) and during (week 4-7) junk-food diet exposure. (b) Average conditioned approach behavior (total CS lever presses and food-cup entries during the CS period) across autoshaping sessions prior to junk-food diet exposure is greater in Junk-Food Gainers vs Junk-Food Non-Gainers. (c) Responding during the inter-trial-interval (ITI; ie, in the absence of the sucrose cue) decreased across sessions and did not differ between groups after acquisition. (d) Average $( \pm$ SEM) sign-tracking (CS lever presses) and (e) goal-tracking (food-cup entries during the CS period) across autoshaping sessions conducted prior to junkfood diet exposure (main effect of group $* p<0.05$ ). 
conditioning, rats subsequently identified as JF-Gainers showed greater cue-triggered approaches to the sucrose cue (sign-tracking) and to the food cup goal-tracking than JF-Non-Gainers (Figure 1b: group $\times$ time interaction $\left.\mathrm{F}_{(7,196)}=2.24, p<0.04\right)$. The rate of acquisition for conditioned approach learning did not differ between groups in the first 3 days of training (Figure $1 \mathrm{~b}$, sessions 1-3) but once established, the magnitude of conditioned approaches to the sucrose-predictive cue was significantly greater in JF-Gainers than JF-Non-Gainers (Figure 1b, sessions 4-8; main effect of group $\left.\mathrm{F}_{(1,28)}=5.54, p=0.02\right)$. In addition, consistent with associative control by the Pavlovian sucrose cue (CS+), foodcup entries during the inter-trial interval (ie, when the cue was absent) did not differ between groups after acquisition (Figure 1c, sessions 4-8: main effect of group and session $\times$ group interaction n.s.), and decreased across training in both groups (Figure 1c: main effect of session $\mathrm{F}_{(7,196)}=22.85$, $p<0.0001)$. Thus, the higher responding by JF-Gainers from session 4 to 8 was truly cue-triggered, and did not occur without the sucrose cue.

Elevated cue-triggered approaches on sessions 4-8 was contributed both by approaches of sign-trackers to the sucrose lever cue (individuals having $\geqslant 66 \%$ of total responses directed towards the CS+ lever; JF-Gainer $N=4$, JF-Non-Gainer $N=15$ ) and by approaches of goal-trackers to the food-cup during cue presentation (individuals having $\geqslant$ $66 \%$ of total responses directed towards the food cup during cue presentation, JF-Gainer $N=3$, JF-Non-Gainer $N=6$ ). Two rats in the JF-Non-Gainer group were intermediates showing similar degrees of sign-tracking and goal-tracking behavior. Specifically, sign-tracking grew stronger across days in JF-Gainers (group $\times$ session interaction $\mathrm{F}_{(7,119)}=$ 3.91, $p<0.0007$ ), while goal-tracking was generally enhanced in JF-Gainers vs JF-Non-Gainers (main effect of group $\left.\mathrm{F}_{(1,56)}=6.98, p=0.01\right)$. Combining these cue-triggered conditioned approach targets together (Figure $1 \mathrm{~b}$ ), a robust increase in Pavlovian attraction to sucrose-predictive stimuli in JF-Gainers over JF-Non-Gainers was revealed, suggesting that JF-Gainers had enhanced cue-triggered attraction to both sucrose-predictive stimuli prior to the development of obesity: the CS+ lever cue that was correlated with sucrose delivery and the dish location where sucrose would actually appear. In addition, on the first 3 days of training (sessions 1-3) food-cup entries during the inter-trial interval were higher in JF-Gainers than JF-Non-Gainers (Figure 1c sessions 1-3: main effect of group $\left.\mathrm{F}_{(1,28)}=5.07, p=0.03\right)$, possibly reflecting initial attraction to the sugar-paired dish before rats had learned the full prediction contingency between CS+ lever and sucrose delivery.

\section{Experiment 2}

Conditioned approach behavior when trained food restricted was examined in a separate set of rats prior to exposure to junk-food. Weight prior to, after, and during food restriction did not differ between rats subsequently identified as JFGainers or JF-Non-Gainers (Supplementary Figure 1), nor did initial weight predict subsequent susceptibility to weight gain.

Junk-food diet-induced weight gain is accompanied by metabolic dysfunction. As above, only some susceptible rats gained significant weight when given free access to the junk-food diet, while others remained the same weight as Chow-Fed rats (Figure 2a; main effect of group, $\mathrm{F}_{(1,11)}=$ 58.03, $p<0.001$; group $\times$ time interaction, $\mathrm{F}_{(27,297)}=12.53$, $p<0.0001$; Chow-Fed $N=10$; JF-Non-Gainer $N=8$; JFGainer $N=5$ ). Even within the first week, JF-Gainers gained significantly more weight than either JF-Non-Gainers or Chow-Fed rats (Figure 2a lower panel; $\mathrm{F}_{(2,20)}=$ 19.09, $p<0.001$; JF-Gainers $v s$ JF-Non-Gainers, $t_{11}=6.05$, $p<0.0001$ and JF-Gainers $v s$ Chow-Fed, $t_{13}=4.63$, $p<0.0005)$, despite no difference in initial weight at the onset of the junk-food diet (Figure 2a lower panel). JFGainers also showed significant increases in plasma leptin and fasted insulin levels after 15 weeks on the junk-food diet compared with JF-Non-Gainers (Figure 2a Lower panels; Leptin: $\mathrm{F}_{(2,19)}=14.22, p<0.001$; JF-Gainers vs JF-NonGainers: $\mathrm{t}_{11}=3.9, \quad p<0.01$, JF-Gainer $\quad v s$ Chow-Fed: $\mathrm{t}_{12}=4.7, p<0.001$; Insulin: $\mathrm{F}_{(2,20)}=4.22, p<0.05$; JF-Gainer vs JF-Non-Gainer: $\mathrm{t}_{11}=2.3, p<0.04$, and JF-Gainer $v s$ ChowFed: $\left.t_{13}=2.67, p<0.02\right)$. Increased leptin levels are consistent with increased fat mass, and increased fasted insulin levels are indicative of metabolic dysfunction (Kennedy et al, 1997). In contrast, leptin and insulin levels were similar in JF-Non-Gainers and Chow-Fed groups.

Food restriction masks pre-existing differences in approach to the sucrose cue. When food restricted, conditioned approach no longer differed between groups (Figure 2b). This was likely due to a ceiling effect introduced by food restriction, as the overall magnitude of responding was much greater in food restricted groups in Experiment $2(133 \pm 4.9)$ than in free-access groups of Experiment 1 (48.2-68 \pm 3.3 1.8). Furthermore, whether rats were trained food restricted or ad lib, individual differences in the tendency towards signtracking or goal-tracking behavior did not differ between JFGainers and JF-Non-Gainers (Figure 2e).

Junk-food gainers show conditioned reinforcement, but junk-food non-gainers do not. After 3 months of ad lib exposure to the junk-food diet, approach to the sucrose cue during extinction and willingness to work for the sucrose cue alone during instrumental conditioned reinforcement were measured in rats from Experiment 2. Extinction was similar between groups and JF-Gainers vs JF-Non-Gainers did not differ during re-acquisition of autoshaping (data not shown).

During conditioned reinforcement testing, JF-Gainers and Chow-Fed rats nose-poked to earn presentations of the sucrose cue alone (in the absence of any actual sucrose), whereas JF-Non-Gainers did not (Figure 2f: main effect of port $\mathrm{F}_{(1,20)}=10.1, p<0.01$; Active $v s$ Inactive JF-Gainer: $\mathrm{t}_{4}=2.5, p<0.04$, Chow-Fed: $\mathrm{t}_{9}=2.6, p<0.04$; JF-Non-Gainer: $\left.\mathrm{t}_{7}=0.47, p=0.33\right)$. Thus, the sucrose cue acquired incentive value (ie, supported instrumental responding) in JF-Gainers and in Chow-Fed rats, but not in JF-Non-Gainers.

Junk-food diet induces cross-sensitization to amphetamine, regardless of weight gain. Amphetamine-induced locomotion did not differ between JF-Gainers and JF-Non-Gainers (Figure 3). However, regardless of weight gain, rats fed the junk-food diet showed stronger amphetamine-induced locomotion (ie, sensitization) compared with Chow-Fed 
rats (Figure 3: main effect of group $\mathrm{F}_{(2,15)}=4.66, p<0.03$; group $\times$ dose interaction, n.s.; Chow-Fed $v s$ Junk-Food: main effect of group $\left.\mathrm{F}_{(1,21)}=10.88, p<0.01\right)$. Time course data for individual amphetamine doses are shown in Supplementary Figure 2 (all statistics for Supplementary Data are given in the figure captions).

Junk-food and obesity-related differences in dopamine and opioid receptor $m R N A$ expression. There were no correlations between mRNA expression and weight gain (Chow
$N=10$, JF-Gainer $N=5$, JF-Non-Gainer $N=8$ ). Further, although differences in sign-tracker and goal-tracker mRNA expression have been previously reported (Huys et al, 2014), there were not enough goal-trackers to evaluate differences here $(\mathrm{GT} N=2)$.

Junk-food decreases D2 mRNA expression, regardless of obesity. D2 mRNA did not differ between JF-Gainers and JF-Non-Gainers in any brain region. However, in the NAc, D2 mRNA expression was significantly decreased in the
Junk-Food Produces Obesity in a Subset of Rats
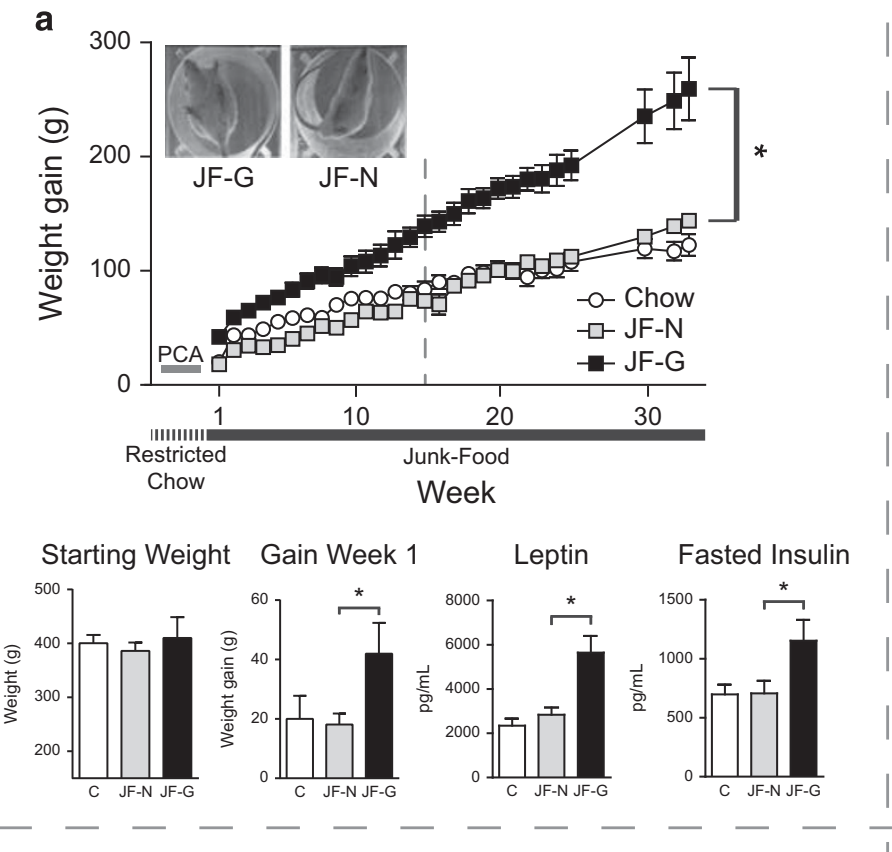

Tendency Towards Sign-Tracking or Goal-Tracking is Similar Between JF-Gainers and JF-Non-Gainers

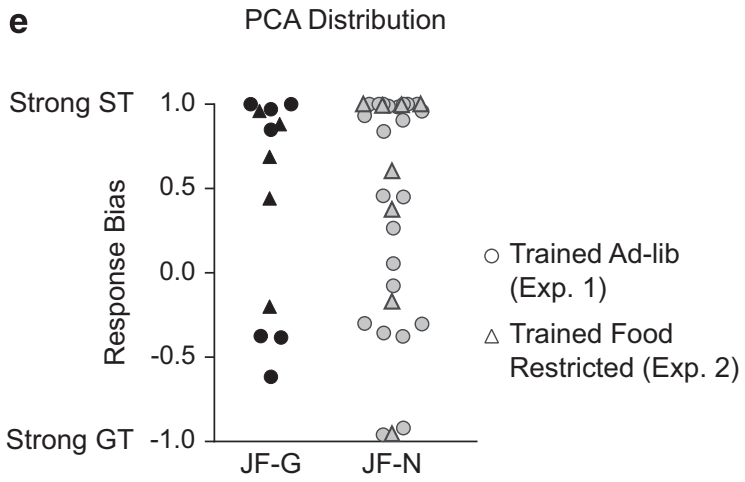

Food Restriction Masks Pre-Existing Differences in Conditioned Approach

b

Conditioned Approach
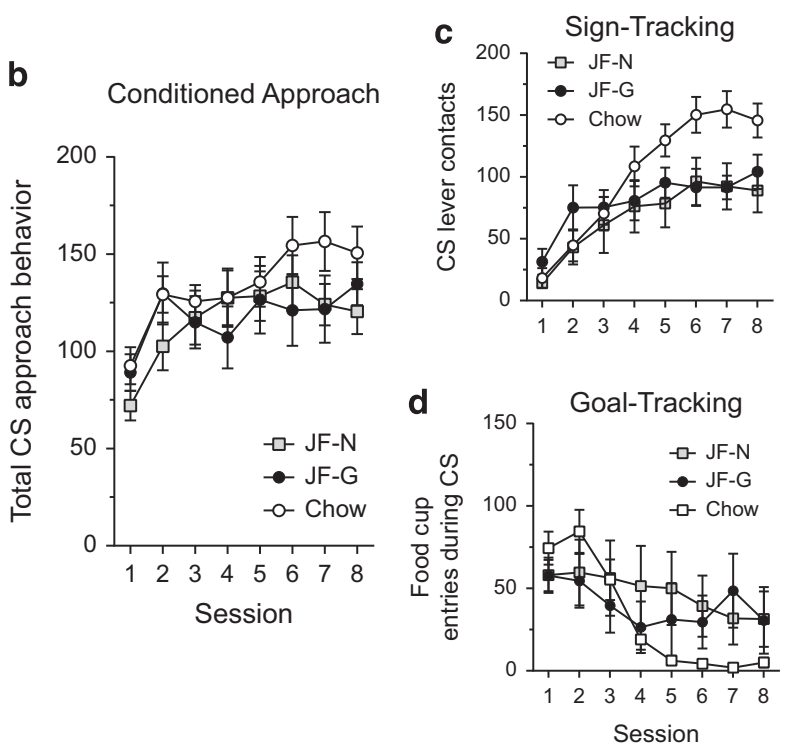

JF-Gainers Will Work for the Sucrose-Cue Whereas JF-Non-Gainers Will Not

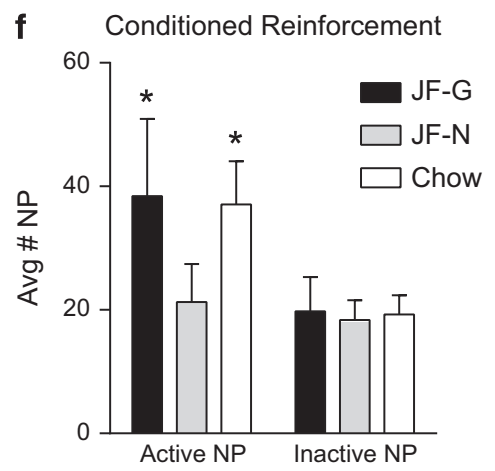

Figure 2 Willingness to obtain the sucrose cue is enhanced in Junk-Food Gainers vs Junk-Food Non-Gainers after junk-food diet exposure and tendency towards sign-tracking and goal-tracking does not 'map on' to susceptibility to obesity. (a) Average $( \pm$ SEM) weekly weight gain (upper panel), whereas lower panels from left to right show: starting weight, weight gain during the first week of junk-food diet exposure, and plasma levels of leptin and fasted insulin after 15 weeks of junk-food diet exposure. (b) Average conditioned approach behavior (total CS lever presses and food-cup entries during the CS period) across autoshaping sessions prior to junk-food diet exposure did not differ between groups when animals were trained food-restricted. (c) Average ( \pm SEM) signtracking (CS lever presses) and (d) goal-tracking (food-cup entries during the CS period) across autoshaping sessions while food-restricted. (e) Bias towards sign-tracking and goal-tracking for individual rats trained while food-restricted (triangles) or trained while ad lib fed (circles) did not differ. (f) Average number $( \pm$ SEM) of active and inactive nose-poke responses during instrumental conditioned reinforcement testing. JF-Gainers and Chow-Fed rats were willing to work for a presentation of the sucrose cue, whereas JF-Non-Gainers were not (active vs inactive; ${ }^{2} p<0.05$ ). 
Junk-Food Produces Cross-Sensitization to Amphetamine, Regardless of Obesity

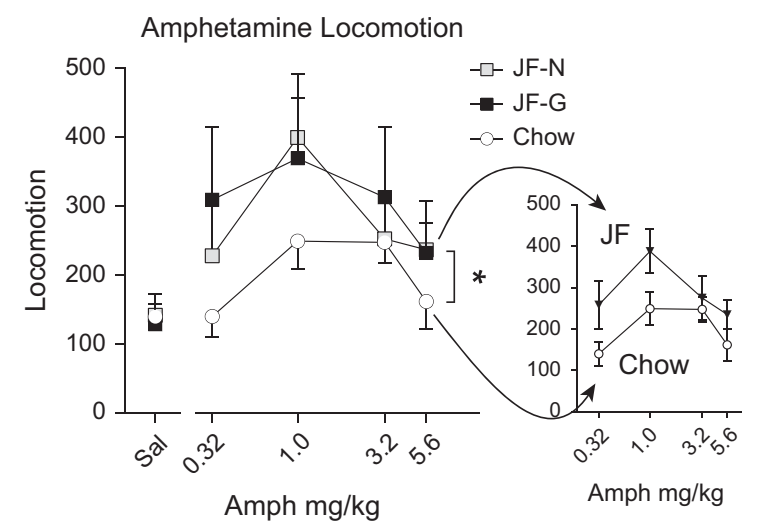

Figure 3 Cross-sensitization to amphetamine. Average number of beam breaks ( \pm SEM) per $25 \mathrm{~min}$ after injection of saline $(\mathrm{I} \mathrm{ml} / \mathrm{kg})$ or 4 doses of $\mathrm{d}$-amphetamine $(0.32, \quad$, $3.2,5.6 \mathrm{mg} / \mathrm{kg}$, i.p.). Regardless of weight gain, rats fed a junk-food diet showed a sensitized locomotor response to amphetamine compared with Chow-Fed rats (main effect of group ${ }^{*} p<0.05$; see also Supplementary Figure 2).

rostral core and rostral shell in all rats that had eaten junkfood for 6 months compared with the Chow-Fed group, regardless of weight gain (Figure $4 \mathrm{a}$ : Core, $\mathrm{t}_{20}=1.82, p<0.05$; Shell, $\left.\mathrm{t}_{20}=2.08, p<0.05\right)$. D2 mRNA expression did not differ in caudal NAc core or caudal shell (Figure 4a), nor in any portion of the $\mathrm{CPu}$ (data not shown).

D1 mRNA expression is greater in junk-food non-gainers. In contrast to D2 mRNA differences, D1R mRNA expression was greater in rostral $\mathrm{CPu}$, rostral NAc core, and rostral shell in JF-Non-Gainers compared with both JF-Gainers and Chow-Fed rats (Figure 4b: main effect of group across regions; Chow-Fed vs JF-Non-Gainer, $\mathrm{F}_{(1,15)}=6.15, p<0.03$; JF-Gainer $v s$ JF-Non-Gainer, $\left.\mathrm{F}_{(1,11)}=12.45, p<0.01\right)$. No differences in D1R mRNA expression were found in caudal $\mathrm{CPu}, \mathrm{NAc}$ core or shell. In the VTA, TH mRNA was lower in JF-Gainers vs JF-Non-Gainers (Figure 4c left panel: $\left.\mathrm{t}_{10}=2.85, p<0.02\right)$, D2R mRNA expression did not differ between groups, and trends towards decreased DAT mRNA expression between Junk-Food and Chow-Fed rats did not reach statistical significance (Figure 4c, DAT mRNA: $\mathrm{t}_{20}=1.75, p=0.09$ ).

$M u$ receptor $(M u R)$ mRNA is lower in junk-food gainers vs junk-food non-gainers. MuR mRNA expression did not differ between JF-Non-Gainers and Chow-Fed rats in any region examined (Figure 5). However, significantly lower expression of MuR mRNA in rostral, but not caudal, NAc shell was found in JF-Gainers vs JF-Non-Gainers (Figure 5a: $\left.\mathrm{t}_{11}=1.8, p<0.05\right)$. Similarly, lower MuR mRNA levels were found in rostral dorsal-medial $\mathrm{CPu}$ (Figure $5 \mathrm{~b}: \mathrm{t}_{11}=2.54$, $p<0.03$ ) and in rostral central $\mathrm{CPu}$ (Figure $5 \mathrm{~d}$ : $\mathrm{t}_{11}=2.86$, $p<0.02)$ in JF-Gainers $v s$ JF-Non-Gainers. In contrast, MuR mRNA expression in all other quadrants of rostral $\mathrm{CPu}$ (dorsallateral, ventral medial, and ventral lateral) and NAc core (rostral/caudal) did not differ between groups (Figure 5c, e-g).

\section{Experiment 3}

Hedonic responses to oral sucrose prior to and after 1 month of junk-food diet exposure, and after acute food restriction were measured in a separate set of rats (JF-Gainer $N=6$, JFNon-Gainer $N=5$ ).

Exposure to a junk-food diet dampens hedonic sensitivity to sucrose concentration. Again, the junk-food diet produced obesity in susceptible rats that was accompanied by increased leptin levels in JF-Gainers (Supplementary Figure 3). Before junk-food exposure, positive oral-facial responses reflecting hedonic impact increased monotonically in all rats as sucrose concentrations increased (Figure 5h, Pre-JF: main effect of sucrose concentration, $\mathrm{F}_{(2,54)}=5.52$, $p<0.01$; pre $1 \%$ vs pre $9 \%$ sucrose, $\left.\mathrm{t}_{9}=4.018, p<0.01\right)$. This initial hedonic response to sucrose did not differ between JF-Gainers and JF-Non-Gainers. By contrast, after 1 month on the junk-food diet, concentrations of sucrose no longer differed in the number of positive hedonic reactions (Figure 5h Post-JF: main effect of sucrose concentration, $\mathrm{F}_{(2,54)}=0.01, p=0.988$; post $1 \%$ vs post $9 \%$ sucrose, $\left.t_{9}=0.591, p=0.57\right)$. Further, positive responses to sucrose were generally higher in the JF-Non-Gainers than JF-Gainers after junk-food diet exposure (Figure 5h Post-JF and Supplementary Figure 4). In addition, although acute food restriction increased positive hedonic responses in both groups, JF-Gainers still showed less strong positive reactions than JF-Non-Gainers and sensitivity to sucrose concentration remained blunted (Supplementary Figure 4D and E).

\section{DISCUSSION}

\section{Motivation for Food Cues}

Food cues often trigger the desire to eat, especially in obese individuals (Kessler, 2009; Tetley et al, 2009; Stice et al, 2010; Demos et al, 2012; Soussignan et al, 2012). In fMRI studies, food cues more strongly activate the NAc and $\mathrm{CPu}$ in obese people (Rothemund et al, 2007; Stoeckel et al, 2008), even prior to the development of obesity (Stice et al, 2010; Demos et al, 2012). Here, we found that prior to weight gain, rats subsequently identified as susceptible to diet-induced obesity (JF-Gainers) showed stronger conditioned approach than rats resistant to diet-induced obesity (JF-Non-Gainers). Enhanced cue-triggered approach was not due to faster learning by JFGainers, as initial acquisition speed did not differ (Figure 1b; sessions 1-3), but to greater levels of cue-triggered attraction to sucrose-associated stimuli once the CS+-sucrose association was learned (Figure 1b; sessions 4-8). This enhanced cue-triggered incentive motivation in JF-Gainers manifested both as higher sign-tracking approaches to CS+ lever, and higher goal-tracking approaches to the dish where sucrose was delivered (the food-cup goal; but only when the CS+ lever was present, and not in its absence). This dual attraction to sucrose-associated stimuli may be analogous to enhanced human cue-triggered attraction both to predictive cues as a blinking sign for donuts, and to the cupboard or counter where the treat may actually be obtained.

Beyond physical attraction to cues, JF-Gainers with access to junk-food were also willing to work on a new instrumental response (nose-pokes) to obtain presentations of the 


\section{a Junk-Food Decreases D2R mRNA in Rostral NAc}

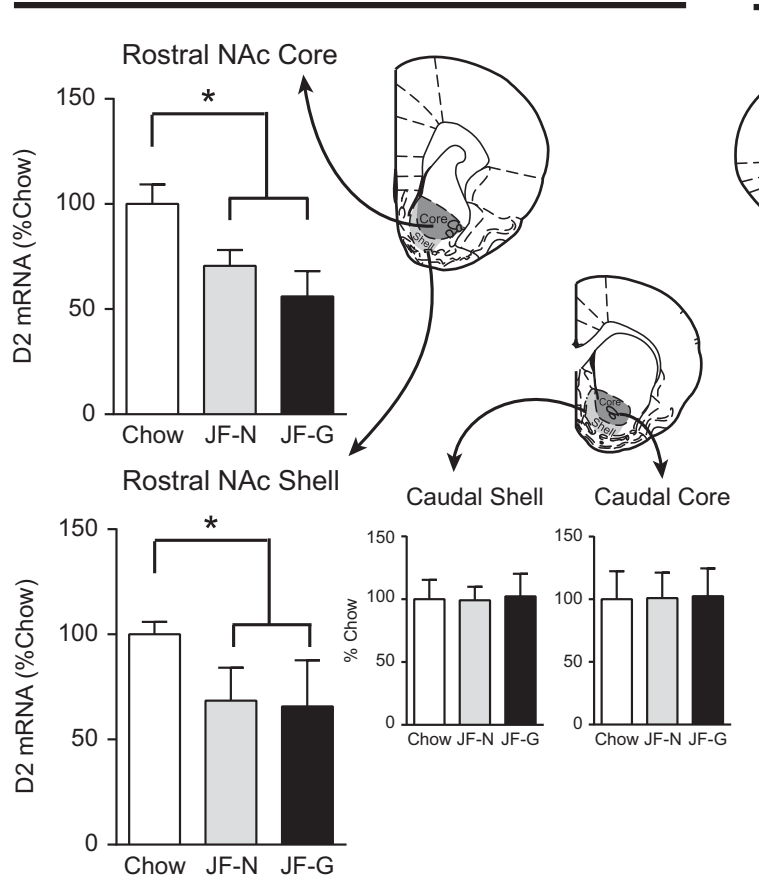

b Increase in Rostral Caudate Putamen D1R mRNA in JF-N vs. JF-G and Chow

c
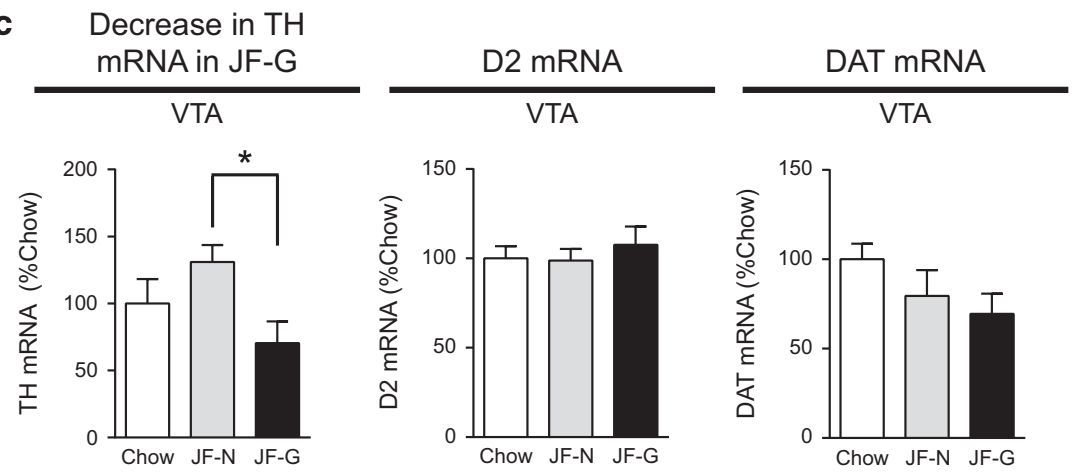

Figure 4 Junk-food diet exposure decreases D2R mRNA expression in rostral NAc, regardless of weight gain. (a) Average D2R mRNA expression $( \pm$ SEM) in the rostral NAc core and shell is decreased in all rats fed a junk-food diet, regardless of weight gain, compared with Chow-Fed rats (Junk-Food vs

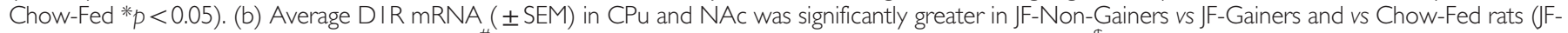

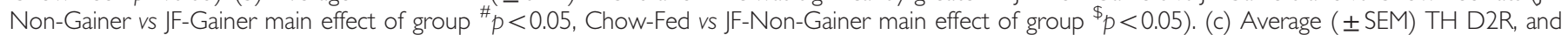
DAT mRNA expression in the VTA. TH mRNA expression was significantly decreased in JF-G vs JF-Ns (* $p<0.05)$.

sucrose cue by itself (CS+ lever insertion without actual sucrose), whereas JF-Non-Gainers did not work for the CS+ (Figure 2f). These data are consistent with enhanced incentive motivation attributed to sucrose cues in rats susceptible to obesity. Finally, differences in cue-triggered motivation (Figure 1b) were not due to initially enhanced 'liking' for sucrose taste, as hedonic responses to sucrose prior to junk-food diet did not differ between subsequently identified JF-Gainer and JF-Non-Gainers (Figure 5h), and later exposure to junk-food diet only tended to dampen sensitivity to sucrose concentration, rather than increase it. Suppression of hedonic reactivity may be consistent with a previous study using lick rate to measure hedonic impact (Shin et al, 2011), though suppressed lick rates were seen at lower sucrose concentrations ( $<0.01 \%$ vs $1-9 \%$ used here). In summary, rats susceptible to diet-induced obesity show greater conditioned approach to Pavlovian sucrose cues prior to obesity, and enhanced motivation to obtain a sucrosepaired cue after junk-food diet exposure and the development of obesity. To our knowledge, this is the first time that enhanced motivation for food cues has been captured in an animal model of obesity that might relate to the enhanced sensitivity to palatable food cues observed in some obese people.

\section{Junk-Food Diet Induces Cross-Sensitization to Amphetamine and Decreases in D2R mRNA Regardless of Obesity}

Regardless of weight-gain, junk-food diet exposure induced cross-sensitization to amphetamine-induced locomotion, and decreases in D2R mRNA expression in the NAc, in 
a

Lower Mu mRNA Only in JF-G NAc Shell 'Liking' Hotspot

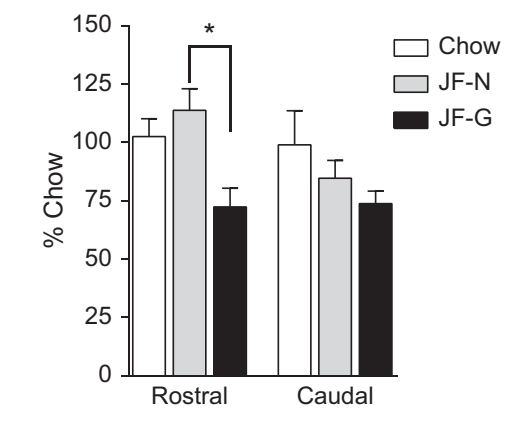

g

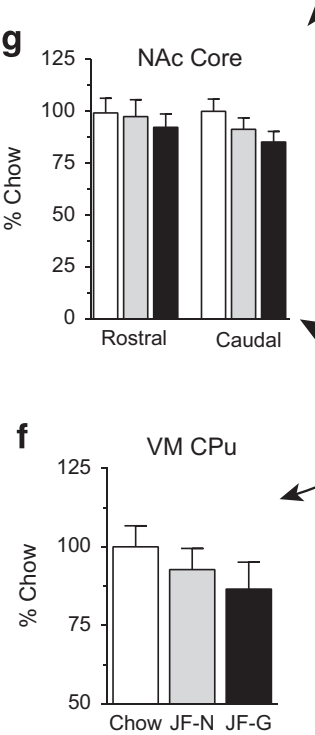

b

Lower Mu mRNA Only in JF-G in CPu 'Wanting' Hotspot

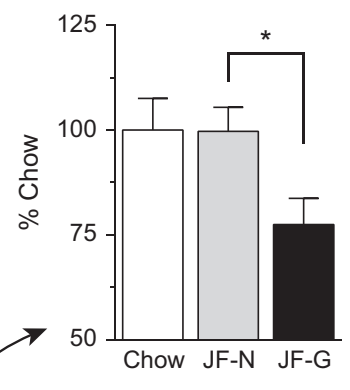

C $\mathrm{DLCPu}$
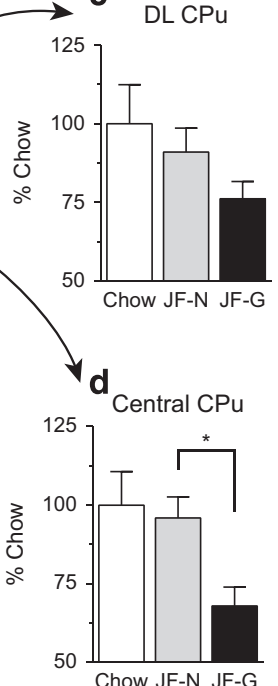

h

Initial Hedonic Responses to Sucrose Do Not Differ, but JF Dampens Sensitivity to Sucrose Concentration

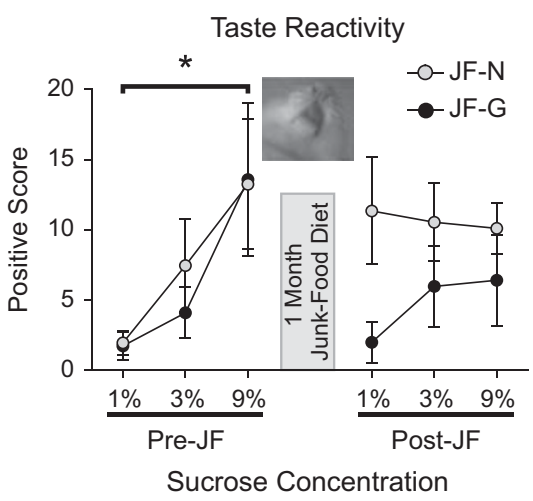

Figure 5 MuR mRNA expression is lower in feeding 'hot-spots' of Junk-Food Gainers vs Junk-Food Non-Gainers and hedonic responses to oral sucrose administration. (a) Average MuR mRNA expression ( \pm SEM) in the rostral shell 'liking' hot-spot and caudal shell, (b) in the dorsal-medial CPu 'wanting' hotspot, and (d) the anterior central CPu are significantly lower in JF-Gainers than in JF-Non-Gainers $(* p<0.05)$. Average MuR mRNA expression $( \pm$ SEM) in dorsal-lateral CPu (c), ventral-lateral CPu (e), ventral-medial CPu (f), and NAc Core (g) did not differ between groups. (h) Average positive hedonic response $( \pm$ SEM) to increasing concentrations of sucrose prior to (Pre-JF) and after I month of junk-food diet exposure (Post-JF). Prior to junk-food diet exposure, hedonic responses to sucrose did not differ in rats subsequently identified as Junk-Food Gainers and Junk-Food Non-Gainers, and increasing concentrations of sucrose elicited increasingly stronger positive hedonic responses (main effect of concentration $* p<0.05$ ). After junk-food diet exposure, all concentrations of sucrose elicited similar levels of positive hedonic responses, with Junk-Food Non-Gainers generally showing stronger positive response than Junk-Food Gainers (see also Supplementary Figure 4).

both JF-Gainers and JF-Non-Gainers. Cross-sensitization to repeated psychostimulant exposure has been reported after binge-fast cycles of sucrose ingestion and after exposure to high-fat foods without the development of obesity (Avena et al, 2008; Baladi et al, 2012, though see also Davis et al, 2008). However, junk-food-induced cross-sensitization here was evident at the first amphetamine exposure, and did not appear to require prior binge-fast cycles. Our results suggest that decreases in NAc D2R mRNA can be a consequence of eating the junk-food diet, regardless of weight gain or individual predisposition. Thus, differences in D2R mRNA expression alone are not likely to be sufficient to explain individual differences in cue-induced motivation. The ability of prolonged junk-food exposure to induce crosssensitization to amphetamine and reduce D2R mRNA here might have been due to repeated activation of mesolimbic brain systems by eating palatable food (eg, elevations in striatal dopamine and endogenous opioids; (Geiger et al, 2009)), or as a satiety-related downregulation response to post-ingestion signals from metabolism of sugary and fatty food. This explanation may also apply to previous reports of downregulation of striatal D2R levels by a palatable 'cafeteria style diet' in non-obese rodents ((Alsio et al, 2010) and Figure 4c, Extended $\mathrm{H} v s$ Extended L in (Johnson and Kenny, 2010)). Downregulation as a consequence of palatable food exposure or overconsumption is also consistent with a clinical report that low D2R levels may be reversed by effective weight-loss surgery in obese individuals that curtails food consumption (Steele et al, 2010, but see also de Weijer et al, 2011; Dunn et al, 2010).

In contrast to D2R mRNA, striatal D1R mRNA expression was higher in JF-Non-Gainers than in JF-Gainers or Chow-Fed 
rats. This is consistent with a previous study that found lower NAc D1R mRNA expression in obese $v s$ non-obese rats given a sugary diet (Alsio et al, 2010). However, based on our comparison to Chow-Fed rats, this difference may be due to elevated D1R mRNA levels in rats that are resistant to dietinduced obesity, and not to lower levels in obesity-prone rats. Whether this difference in D1R mRNA is pre-existing $v s$ dietinduced requires the ability to identify obesity-resistant and susceptible rats without diet manipulation. None-the-less, taken together our data suggest that the balance of D1 vs D2 receptor-mediated transmission may differ substantially in Junk-Food-Gainers vs Junk-Food-Non-Gainers.

\section{Mu Receptor mRNA Expression}

JF-Gainers had lower levels of MuR mRNA compared with JF-Non-Gainers in two discrete regions of the striatum: a rostral NAc shell 'liking hot-spot' in which MuR activation enhances positive orofacial reactions to sucrose taste, and a dorsal-medial $\mathrm{CPu}$ 'wanting hot-spot' in which activation of MuR induces intense consumption of palatable foods (DiFeliceantonio et al, 2012). Although we cannot conclusively rule out the contribution of pre-existing differences, our taste-reactivity data suggest that lower MuR mRNA expression may be a consequence of junk-food diet exposure and/or the development of obesity in susceptible rats. First, hedonic responses to sucrose were identical in JF-Gainers and JF-Non-Gainers prior to junk-food diet exposure (Figure 5h), suggesting that neural 'liking' systems did not initially differ. Second, after junk-food diet exposure, JF-Gainers showed lower hedonic reactions ('liking') to sucrose, as would be expected if MuR-mediated transmission were decreased and may be related to excessive alliesthesia accompanying obesity. Given that endogenous enkephalin levels rise rapidly at the onset of palatable food consumption in the dorsal-medial $\mathrm{CPu}$ 'wanting hot-spot', consequent downregulation of MuR mRNA in this region could be due to repeated activation of MuR by palatable food consumption (Lenard et al, 2010; Shin et al, 2010). Thus, decreased MuR mRNA levels in both striatal regions may be a consequence of junk-food diet consumption and obesity in Junk-Food-Gainers. This interpretation is also consistent with progressive decreases in striatal reactivity to palatable foods as people gain additional weight (Stice et al, 2010).

\section{Summary}

Debate exists concerning the mechanisms underlying individual differences in eating and obesity. Some have proposed that pre-existing hypoactivity of mesocorticolimbic systems produces 'reward deficiency' that drives over-eating (Johnson and Kenny, 2010; Parylak et al, 2011). By contrast, others propose that opposite hyperreactivity of these systems drives elevated cue-triggered motivation to eat (Davis et al, 2009; Gearhardt et al, 2011; Stice et al, 2012; Volkow et al, 2013a). Both hypotheses recognize that individual differences are important (Berthoud, 2012); indeed differences in sensitivity to leptin, insulin, and post-meal satiety have been associated with susceptibility to diet-induced obesity (Levin et al, 2004; Clegg et al, 2005; Cottone et al, 2007). Although further studies are needed to distinguish pre-existing and diet/obesity-induced differences in mesolimbic function, our results clearly demonstrate that some aspects of mesolimbic function are influenced primarily by exposure to palatable foods regardless of weight gain (D2R mRNA and amphetamine-induced locomotion), whereas other aspects (incentive-motivation, MuR, D1R mRNA) are influenced by individual differences that likely represent interactions between pre-existing and experience-induced plasticity. Furthermore, our data suggest that pre-existing increases in food-cue-induced motivation may contribute to the development and persistence of obesity in susceptible individuals (see also Burger and Stice, 2014). This pre-existing sensitivity to food cues may be further exacerbated by palatable food consumption and/or physiological alterations that accompany obesity. This pattern is similar to incentivesensitization that may underlie drug addiction (Robinson and Berridge, 2008; Vezina and Leyton, 2009). Although addiction labels must be used cautiously, and important differences between drugs and food must be considered (eg, drug addicts may seek abstinence, whereas obese individuals strive for controlled consumption), the potential overlap and distinctions in underlying neural mechanisms remains an interesting and promising avenue for research and treatment development (Avena et al, 2008; Kenny, 2011; Volkow et al, 2013b).

\section{FUNDING AND DISCLOSURE}

The authors declare no conflict of interest.

\section{ACKNOWLEDGMENTS}

We thank Dr Terry E Robinson for use of locomotor testing chambers, Dr Mark EJ Newman for writing the diet composition program, Dr Jason Whalen for Mulitplex analysis, Hong Keun Yoon, Kate Dykhuis, and Jim Stewart for technical assistance, and Dr Peggy E Gnegy and Dr Paul J Meyer for helpful conversations. This work was funded by MH63649 and DA015188 to KCB awarded by NIMH and NIDA, and DK092322 to PRB awarded by NIDDK and utilized the Chemistry Core of the Michigan Diabetes Research and Training Center funded by DK020572 awarded by NIDDK. Dr Mike Robinson is currently an Assistant Professor of Psychology and Neuroscience \& Behavior at Wesleyan University, Middletown, CT 06459.

\section{REFERENCES}

Alsio J, Olszewski PK, Norback AH, Gunnarsson ZE, Levine AS, Pickering $C$ et al (2010). Dopamine D1 receptor gene expression decreases in the nucleus accumbens upon long-term exposure to palatable food and differs depending on diet-induced obesity phenotype in rats. Neuroscience 171: 779-787.

Anselme P, Robinson MJ, Berridge KC (2013). Reward uncertainty enhances incentive salience attribution as sign-tracking. Behav Brain Res 238: 53-61.

Avena NM, Rada P, Hoebel BG (2008). Evidence for sugar addiction: behavioral and neurochemical effects of intermittent, excessive sugar intake. Neurosci Biobehav Rev 32: 20-39.

Baladi MG, Daws LC, France CP (2012). You are what you eat: influence of type and amount of food consumed on central dopamine systems and the behavioral effects of direct- and 
indirect-acting dopamine receptor agonists. Neuropharmacology 63: 76-86.

Berridge KC (2000). Measuring hedonic impact in animals and infants: microstructure of affective taste reactivity patterns. Neurosci Biobehav Rev 24: 173-198.

Berthoud HR (2012). The neurobiology of food intake in an obesogenic environment. Proc Nutr Soc 71: 478-487.

Burger KS, Stice E (2014). Greater striatopallidal adaptive coding during cue-reward learning and food reward habituation predict future weight gain. Neuroimage 99: 122-128.

Clegg DJ, Benoit SC, Reed JA, Woods SC, Dunn-Meynell A, Levin BE (2005). Reduced anorexic effects of insulin in obesityprone rats fed a moderate-fat diet. Am J Physiol Regul Integr Comp Physiol 288: R981-R986.

Cottone P, Sabino V, Nagy TR, Coscina DV, Zorrilla EP (2007). Feeding microstructure in diet- induced obesity susceptible versus resistant rats: central effects of urocortin 2. J Physiol 583(Pt 2): 487-504.

Dagher A (2009). The neurobiology of appetite: hunger as addiction. Int J Obes 33(Suppl 2): S30-S33.

Davis CA, Levitan RD, Reid C, Carter JC, Kaplan AS, Patte KA et al (2009). Dopamine for "wanting" and opioids for "liking": a comparison of obese adults with and without binge eating. Obesity (Silver Spring) 17: 1220-1225.

Davis JF, Tracy AL, Schurdak JD, Tschop MH, Lipton JW, Clegg DJ et al (2008). Exposure to elevated levels of dietary fat attenuates psychostimulant reward and mesolimbic dopamine turnover in the rat. Behav Neurosci 122: 1257-1263.

de Weijer BA, van de Giessen E, van Amelsvoort TA, Boot E, Braak B, Janssen IM et al (2011). Lower striatal dopamine D2/3 receptor availability in obese compared with non-obese subjects. EJNMMI Res 1: 37.

Demos KE, Heatherton TF, Kelley WM (2012). Individual differences in nucleus accumbens activity to food and sexual images predict weight gain and sexual behavior. J Neurosci 32: 5549-5552.

DiFeliceantonio AG, Mabrouk OS, Kennedy RT, Berridge KC (2012). Enkephalin surges in dorsal neostriatum as a signal to eat. Curr Biol 22: 1918-1924.

Dunn JP, Cowan RL, Volkow ND, Feurer ID, Li R, Williams DB et al (2010). Decreased dopamine type 2 receptor availability after bariatric surgery: preliminary findings. Brain Res 1350: 123-130.

Fedoroff IC, Polivy J, Herman CP (1997). The effect of pre-exposure to food cues on the eating behavior of restrained and unrestrained eaters. Appetite 28: 33-47.

Gearhardt AN, Yokum S, Orr PT, Stice E, Corbin WR, Brownell KD (2011). Neural correlates of food addiction. Arch Gen Psychiatry 68: $808-816$.

Geiger BM, Haburcak M, Avena NM, Moyer MC, Hoebel BG, Pothos EN (2009). Deficits of mesolimbic dopamine neurotransmission in rat dietary obesity. Neuroscience 159: 1193-1199.

Ho CY, Berridge KC (2013). An orexin hotspot in ventral pallidum amplifies hedonic 'liking' for sweetness. Neuropsychopharmacology 38: $1655-1664$.

Holland PC, Petrovich GD (2005). A neural systems analysis of the potentiation of feeding by conditioned stimuli. Physiol Behav 86: 747-761.

Huys QJ, Tobler PN, Hasler G, Flagel SB (2014). The role of learning-related dopamine signals in addiction vulnerability. Prog Brain Res 211: 31-77.

Johnson PM, Kenny PJ (2010). Dopamine D2 receptors in addiction-like reward dysfunction and compulsive eating in obese rats. Nat Neurosci 13: 635-641.

Kabbaj M, Devine DP, Savage VR, Akil H (2000). Neurobiological correlates of individual differences in novelty-seeking behavior in the rat: differential expression of stress-related molecules. $J$ Neurosci 20: 6983-6988.
Kennedy A, Gettys TW, Watson P, Wallace P, Ganaway E, Pan Q et al (1997). The metabolic significance of leptin in humans: gender-based differences in relationship to adiposity, insulin sensitivity, and energy expenditure. J Clin Endocrinol Metab 82: $1293-1300$

Kenny PJ (2011). Common cellular and molecular mechanisms in obesity and drug addiction. Nat Rev Neurosci 12: 638-651.

Kessler DA (2009). The end of overeating: taking control of the insatiable American appetite. Rodale Books.

Lenard NR, Zheng H, Berthoud HR (2010). Chronic suppression of mu-opioid receptor signaling in the nucleus accumbens attenuates development of diet-induced obesity in rats. Int J Obes 34: 1001-1010.

Levin BE, Dunn-Meynell AA, Balkan B, Keesey RE (1997). Selective breeding for diet-induced obesity and resistance in Sprague-Dawley rats. Am J Physiol 273(2 Pt 2): R725-R730.

Levin BE, Dunn-Meynell AA, Banks WA (2004). Obesity-prone rats have normal blood-brain barrier transport but defective central leptin signaling before obesity onset. Am J Physiol Regul Integr Comp Physiol 286: R143-R150.

Mansour A, Meador-Woodruff JH, Bunzow JR, Civelli O, Akil H, Watson SJ (1990). Localization of dopamine D2 receptor mRNA and D1 and D2 receptor binding in the rat brain and pituitary: an in situ hybridization-receptor autoradiographic analysis. $\mathrm{J} \mathrm{Neu}$ rosci 10: 2587-2600.

Parylak SL, Koob GF, Zorrilla EP (2011). The dark side of food addiction. Physiol Behav 104: 149-156.

Paxinos G, Watson CJ (2007). The Rat Brain in Stereotaxic Coordinates, 6th edn. Academic Press: MA, USA.

Robinson TE, Berridge KC (2008). Review. The incentive sensitization theory of addiction: some current issues. Philos Trans $R$ Soc Lond B Biol Sci 363: 3137-3146.

Robinson TE, Flagel SB (2009). Dissociating the predictive and incentive motivational properties of reward-related cues through the study of individual differences. Biol Psychiatry 65 869-873.

Rothemund Y, Preuschhof C, Bohner G, Bauknecht HC, Klingebiel $\mathrm{R}$, Flor $\mathrm{H}$ et al (2007). Differential activation of the dorsal striatum by high-calorie visual food stimuli in obese individuals. NeuroImage 37: 410-421.

Shin AC, Pistell PJ, Phifer CB, Berthoud HR (2010). Reversible suppression of food reward behavior by chronic mu-opioid receptor antagonism in the nucleus accumbens. Neuroscience 170: 580-588.

Shin AC, Townsend RL, Patterson LM, Berthoud HR (2011). "Liking" and "wanting" of sweet and oily food stimuli as affected by high-fat diet-induced obesity, weight loss, leptin, and genetic predisposition. Am J Physiol Regul Integr Comp Physiol 301: R1267-R1280.

Soussignan R, Schaal B, Boulanger V, Gaillet M, Jiang T (2012). Orofacial reactivity to the sight and smell of food stimuli. Evidence for anticipatory liking related to food reward cues in overweight children. Appetite 58: 508-516.

Steele KE, Prokopowicz GP, Schweitzer MA, Magunsuon TH, Lidor AO, Kuwabawa $\mathrm{H}$ et al (2010). Alterations of central dopamine receptors before and after gastric bypass surgery. Obes Surg 20: 369-374.

Stice E, Figlewicz DP, Gosnell BA, Levine AS, Pratt WE (2012). The contribution of brain reward circuits to the obesity epidemic. Neurosci Biobehav Rev 37(9 Pt A): 2047-2058.

Stice E, Yokum S, Bohon C, Marti N, Smolen A (2010). Reward circuitry responsivity to food predicts future increases in body mass: moderating effects of DRD2 and DRD4. NeuroImage 50: 1618-1625.

Stoeckel LE, Weller RE, Cook EW 3rd, Twieg DB, Knowlton RC, Cox JE (2008). Widespread reward-system activation in obese 
women in response to pictures of high-calorie foods. NeuroImage 41: 636-647.

Tetley A, Brunstrom J, Griffiths P (2009). Individual differences in food-cue reactivity. The role of BMI and everyday portion-size selections. Appetite 52: 614-620.

Thompson RC, Mansour A, Akil H, Watson SJ (1993). Cloning and pharmacological characterization of a rat mu opioid receptor. Neuron 11: 903-913.
Vezina P, Leyton M (2009). Conditioned cues and the expression of stimulant sensitization in animals and humans. Neuropharmacology 56(Suppl 1): 160-168.

Volkow ND, Wang GJ, Tomasi D, Baler RD (2013a). The addictive dimensionality of obesity. Biol Psychiatry 73: 811-818.

Volkow ND, Wang GJ, Tomasi D, Baler RD (2013b). Obesity and addiction: neurobiological overlaps. Obes Rev 14: $2-18$.

Supplementary Information accompanies the paper on the Neuropsychopharmacology website (http://www.nature.com/npp) 